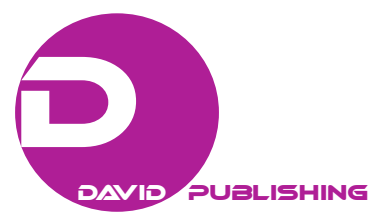

\title{
Globalization as a Social Utopia: Towards the Modern Sociological Criticism of a Mythological Discourse
}

\author{
Alexander V. Petrov \\ Saint-Petersburg State University, Saint Petersburg, Russia
}

\begin{abstract}
The article presents a social analysis of global transformation processes. The global transformation processes are treated as contradictory. These processes are not as positive as the negative impact on the system of modern societies. Globalization as a popular ideology is based on the mythologizing of global neoliberal pseudo-integration, standardlization and unification. Thus it was formulated mythological discourse of global changes research. Apology of this mythological discourse became the intellectual foundation of globalization as a new social utopia. The article presents a critique of the mythological discourse of globalization. The ideology of globalization is interpreted as social dystopia.
\end{abstract}

Keywords: globalization, social science, mythological discourse, neoliberal ideology, modern societies, social utopia, social dystopia

Just 15 years ago, globalization was one of the most popular, widely used terms. Speculations about the reasons and consequences of the state of the global transformation of socio-economic and political processes for almost two decades, is a part of the discourse of contemporary social sciences. And the more there are researches on global changes, the more often the politicians and journalists are spoken about such changes, the more vague and less clear became the term "globalization" that these changes are trying to identify.

Globalization in all its guises originally considered, and still consider, first of all, as a natural result of the process of social evolution of Western society, designed the "project of modernity", which features are universal and therefore "objectively" shall apply to all existing "modern" society, rapidly destroying the "old" world order, based on the reproduction of national and state identities, and replacing its universal system of so-called "democratic global governance".

The second half of the first decade of the XXI century is characterized by the beginning of the process of "the destruction of the ideological model of global integration"-integration for the sake of "general well-being" of humanity - and the gradual elimination of the illusion of the possibility of realization in the foreseeable future "global unity" model spread "uniform system" of social, political, economic institutions and the widespread approval of standards of the "civilized world" in exchange for the sovereignty of countries spanning the last quarter of the XX century centripetal tendencies in the orbit of a "new world order".

It is becoming increasingly important researches aimed at identifying opportunities and prospects for the implementation of ideas restore social and state identity, preservation of national identity and the formation of

Alexander V. Petrov, Ph.D. (sociology, economic sociology), Professor of Saint-Petersburg State University, Department of Sociology, Director of the Russian-Chinese Center for Comparative Social, Economic and Political Researches, Russia. 
the prerequisites for a self-sustaining (sustainable) development in the conditions a considerably complicated, sharply differentiated and highly unstable system of modern international socio-political and economic relations.

It is therefore important to understand what globalization really means. In my view, globalization means global intellectual construct, social utopia or, rather, anti-utopia (dystopia). As a utopia, it consists of a number of social myths. These myths look very positive and promising for many people in the modern world because these myths reflect only the external, explicit manifestations of highly complex, long-term, deep-seated and really not very positive changes in modern societies system (in analysis of the true causes of which the ideologists of globalization were never interested). Moreover this utopia for a long time even claimed to be the new universal global ideology.

This ideology, for all its claims to novelty, has become just another attempt to justify the geopolitical domination of the "capitalist countries", the preservation of geo-economic dominance and the emergence of new opportunities for the expansion of "traditional" industrialized countries.

Like any other ideology, the ideology of globalization is based on a number of myths, which are widespread and entrenched in the social consciousness. For example, the myth means that globalization is manifesting itself in a radical intensification of cross-border social contacts over the past 20-30 years old, is a fundamentally "new" phase of development of civilization, in which mankind finally for the first time in the history is establishing itself as unified totality of interdependent societies. Or on the idea of globalization as a process of dissemination of "mass culture", as a system of universal standards of "civilized life" and the formation on their basis of a new "global coalition of cultures" or "global culture of civilized societies". However, perhaps the most common is the myth of globalization as an unprecedented integration of national states and economies through the development of new information technologies and the establishment of a "global information society", in which should disappear preventing "global progress and modernization" of national borders. In the course of globalization, should significantly reduce the role of the national markets in favor of forming a "free” global market - the sphere of "effective operation" of the world financial centers (for "equitable" distribution in the world economy of investment capital, goods and resources) and transnational corporations ("promoting" the global spread of innovation and their implementation in production and management, and ultimately, a global "inclusive" scientific and technological progress). Thus, a question is an opportunity and, most importantly, the need for self-realization of the political activity of the national governments. From modern states require only one thing-do not interfere with the global integration, delegated powers of the national public administration to international "neoliberal" economic and political organizations, which (thanks to the "global neoliberal modernization" and the spread of "mass culture" of "universal" values) can finally deliver all society from the "remnants of the authoritarian past" like "nation-state identity" and "economic and political interests of the state". Thus, globalization ideology is based on the fundamental myth of the "natural" and "inevitable" process of rapidly increasing interconnectedness of societies and states, which are included in the system of contemporary international relations, which is carried out by erasing the national-state differences, the erosion of the traditional "political-territorial ideal of statehood" and assumptions and interference in the internal affairs of the outside.

A powerful impetus to the development and rooting of this ideology in the social consciousness was given by the political euphoria of the early 1990-ies (reigned not only in Western countries), associated with the end 
of the "cold war", the collapse of the USSR and the beginning of a significant geopolitical transformation-the formation of the system "unipolar" international relations, led by the leading "capitalist democracies".

However, if you rely on the results of contemporary social research, globalization can be defined as a collection of diverse, divergent, ambiguous processes which take place hundreds of years in the history of mankind and which are forming a very complex communication system of modern societies. These processes are in reality far from the myths that characterize globalization as a modern social utopia. These processes are so contradictory and mutually exclusive, that to say about the formation on their basis of a unity, of universal integrity, global community of different countries with totally opposing geopolitical interests, economies with business systems, occupying an unequal position in the international division of labor, civilizations with a unique socio-cultural way of life-either now or in the near future, it is impossible.

Economic globalization, with which (for various reasons) is often equated globalization in general, includes a number of highly contradictory processes, which have ambiguous consequences for all countries in the system of modern societies and modern capitalist system. These consequences are determined by the role played by the country in the modern international division of labor and the status in the system of global economic relations. The role and status is largely determined by global political, socio-cultural and socio-stratification processes, the analysis of which is also important for the understanding of the fundamental contradictions of global economic processes. However, the modern researches on economic globalization, affecting the lives of billions of people, are revealing basic contradictions of globalization, destroying the myth of globalization (in all its "forms") as "objective” and "mutually beneficial” process of universalization and integration of communities, states, national economies.

For years the apologists of globalism argued that globalization, "reshaping our lives", in particular, manifests itself: in the expansion and acceleration of international financial flows and operations, in the internationalization (capitalistic transnationalization) of the industry, in the process of expansion and liberalization of international trade, in the global information and the liberalization of international political relations. During many years, these processes have been mythologized and also became the basis of globalization as a social utopia.

For many years it was assumed that financial globalization contributes to a more "efficient" allocation and use of capital investment in all areas of the global economy. Global internationalization (or transnationalization) industry allows developed countries to reduce costs and, consequently, to reduce prices (on consumed worldwide goods produced by transnational corporations), and many developing countries-involved in the process of transnationalization, which, if be created "favorable investment climate", should lead to the rapid spread of high technologies, modernization of fixed assets, increase productivity, create new jobs, improve the competitiveness of national enterprises, sustainable economic growth and, consequently, to solution all problems of the third world countries. The process of expansion and liberalization of international trade (subject to global neoliberal doctrine of free trade, distribution unified organizational and legal standards of business, and the active support of the international economic and political organizations (OECD, WTO, IMF and so on)) contributes to the establishment of a single "free" world market, strengthening the "healthy" international competition among global producers of goods, as well as the dissemination of international standards of consumption and, consequently, the "civilized" way of life. The process of global information contributes to accelerating flows of the investment capital and goods, contributes to the international exchange of intellectual capital, as an "engine" of the global socio-economic development, and the formation of 
ultra-modern "information economy", "knowledge economy” on a global scale. The process of global liberalization of international political relations, implemented through enhanced monitoring of compliance with common to all the "rules" of international "liberal" political structures, promoting the principles of "democratic" governance, promotes the formation of a universal institutional framework of the economic and political activity, as well as, as a result, it leads to a substantial reduction of "international tension" and "harmonization" of relations between different countries, since, as it was noted in the late 1990s, for example, by A. Giddens, after the end of "cold war" for the majority of countries there are no more enemies [1].

But the reality of modern global processes destroys these illusions, which form the basis of a new social utopia and mythological discourse of globalization. The social consequences of the processes that make up the essence and accompany globalization, are far from basic characteristics of global changes as global processes of increasing "interdependence" of nations and the establishment of a unified system of "mutually beneficial" global cooperation. The sharp increase in the mobility of capital only contributes to the accelerated accumulation of fictitious capital, detached from the real movement of tangible assets and, thus, leads to the formation of the prerequisites for the global financial and economic crises, causing serious damage to national economies of developing countries and the world production. The flip side of the transnationalization process in developed countries is the appearance of depressed regions due to the mass export of businesses and jobs to countries with cheap labor, an increase in unemployment, the dismantling of "social state". For developing countries, transnationalization, which is accompanied by the rapid growth of direct foreign investment, increases the financial and economic dependence on the world's financial centers and multinational companies, increases the debt problems of these countries and negative consequences for the national economies from the periodic destabilization of the global financial system. The introduction of new technologies in branches of transnational corporations, as a rule, does not encourage to self-creation of such technologies by developing countries, which leads to the erosion of the intellectual capital of the country (which manifests itself, for example, in the process of "brain drain”). Transnationalization leads to a significant increase in disparities between the highly profitable enterprises of the industries, which take part in the transnationalization process (and therefore relevant to the world market) and enterprises of the industries in which transnational corporations are not interested (and therefore the world market does not need). Thus transnationalization is profitable only for large international capital and unfavorable for national producers of goods. The global liberalization of trade and economic relations on the basis of dissemination of unified standards strengthens the difference in the real situation of residents and non-residents in the domestic market. Residents lose their competitiveness because they do not correspond to the unified global standards. And non-residents receive an additional competitive advantage in the form of a favorable investment climate for modern enterprises and companies that meet global standards. This situation leads to the death of national enterprises and creation of conditions for long-term unemployment on a global scale. Global trade liberalization also leads to the spread of global standards and values of the consumer society. This is one of the reasons for the destruction of the traditional labor ethics, which is the basis of life of the proletariat [2]. Global informatization fundamentally changes the nature of the labor. Global informatization promotes the separation of the economy (global and national) on the "real" (nationally oriented production) and "virtual" (the world's financial centers), strengthening the influence of the "demonstration effect". Global informatization, along with financial globalization, transnationalization and trade liberalization, creates the preconditions for a global disintegration and marginalization of workers in poor countries, the emergence of new communication barriers. 
More than a hundred years ago, the possibility of forming such modern social utopia based on the synthetic ethics of economism could foresee the famous Russian philosopher and writer Sergei Bulgakov. This synthetic ethics of economism transforms globalization from social utopia into social dystopia. The synthetic ethics of economism opposes the traditional ethics of creative labor and active, genuine culture. This specific and artificial system of ideas and views deforms the spiritual basics of labor and activity of a person in the longer term. That is exactly the reason why the search for an alternative self-realization of modern people is so important. These alternative ways to achieve self-realization have deep philosophical and cultural roots. Modern globalized culture develops in these rigorous frameworks of the kingdom of necessity, which is increasingly being transformed into the kingdom of stable dependence on the opportunity to consume more and more goods. The modern global kingdom of necessity shapes a special aesthetics - the aesthetics of economic fear. Moreover, people feel this fear in spite of their income level or their belonging to this or another social group. It is the fear of losing this opportunity to consume more and more faceless things created and promoted by the global industrial system, their possession gives a constantly false perception of a comfortable life. Modern people are more afraid of losing an opportunity to possess things than to lose themselves. This fear ruins the aesthetics of creative labor. The global economism exists as long as such a fear is in place. One of the main aims of modern people and humankind is to overcome this fear. To achieve this there are the opportunities that include the reorientation of people to the spiritual world, creative labor aiming at self-improvement and creative conversion of reality. This self-improvement can be possible only on the bases of aesthetic of creative labor. Our life is creativity, not only the function of goods reproduction. The economic life is creativity as well. The revival of the labor creative aesthetics exists possibly on a different intellectual basis that is simply the opposite to the dominant modern ideology of economism. The successful impact of economism is based on the fair labor aesthetic. The forming of other intellectual pillars, and overcoming the aesthetics of economic fear is impossible without any experience. The philosophical ideas of Sergei Bulgakov are the basis for forming a new conception, which allows to overcome the ideology of globalization as a dystopia [2].

The ideology of globalization was initially created and promoted as a beautiful social utopia. But real global changes indicate that the ideology of globalization designed to disguise the real social contradictions in the modern societies system and capitalist global economy. This is reason, that globalization can be interpreted as a social dystopia.

\section{Notes}

Giddens, Anthony. (1999). Runaway World: How Globalization is Reshaping Our Lives. London: Profile.

Maria S. Baynova, Tatiana A. Evstratova, Alexander V. Petrov, Ariadna A. Petrova and Olesya A. Volchenkova. (2016). Modern Transformation of Labor Culture and Aesthetics in the Light of Sergei Bulgakov's Religious Philosophy. The Social Sciences, 11, 1414-1421. DOI: 10.3923/sscience.2016.1414.1421

彼得罗夫A. B. 现代世界经济转变中的劳动美学/马克思主义美学研究。第14卷。第2期/王杰主编。一一北京: 中央编译出 版社, 2012.3. 